\title{
ANALYSIS OF REFRIGERANTS RELATING TO THEIR IMPACT ON THE ENVIRONMENT
}

\author{
Krasimir Ivanov \\ Trakia University, Faculty of Technics and Technology, Yambol, Bulgaria \\ 38 "Graf Ignatiev" str., 8600 Yambol, Bulgaria, \\ e-mail: krasimirivanov1978@abv.bg
}

\begin{abstract}
In the present article is analyzed the refrigerants and their impact on the environment according to the Bulgarian and European legislation. Here is discussed and analyzed the proposed methodology for determining the total equivalent warming potential.
\end{abstract}

Keywords: refrigerants, energy efficiency, environment

\section{INTRODUCTION}

Climate change, which is towards global warming, is a major problem at present. If the situation is not well in hand it will cause irreversible impacts on Earth and life on it. For this crucial role has humanity whose activities beyond natural cycles causes anthropogenic (i.e. caused by human activity) global warming. Emission of carbon dioxide emissions and other gases in the atmosphere such as methane, which has a significantly higher warming potential than $\mathrm{CO}_{2}$, causing the so-called greenhouse effect, which reflected from the Earth and solar radiation (mainly infrared) cannot dissipate in space, and comes back and further warms the Earth. Ozone depletion in the southern hemisphere reached unprecedented levels in 1998. It is observed severe ozone depletion over the Arctic region. Increased radiation of UV-B radiation due to ozone depletion poses a significant threat to health and the environment. This requires all countries active actions and decisions to improve energy efficiency and reduce greenhouse gas emissions [7].

These commitments are described in the first ever international agreement on regulation of substances that deplete the ozone layer, signed in 1987 called Montreal Protocol. Since then it has been ratified by 196 countries. Its aim is to phase out various substances with ozonedepleting potential, including chlorofluorocarbons and hydrochlorofluorocarbons, which are often used as fuel or in refrigeration and air conditioning systems. Framework Convention of the United Nations on Climate Change in 1992 in Rio de Janeiro, ratified by the Republic of Bulgaria in 1995 [3], aims to stabilize "greenhouse gas" emissions at the level from 1990. In 1997 in Kyoto (Japan) was adopted document known as the Kyoto Protocol [5], which provides for such emissions to be shortened by an average of $5.8 \%$ the major greenhouse gases (carbon dioxide, methane, nitrous oxide and produced by the people of fluorinated greenhouse gases) in the period 2008-2012.

The European Parliament and the Council adopted on 17 May 2006 Regulation (EC) № $842 / 2006$ on certain fluorinated greenhouse gases (F-Gas Regulation). This regulation is valid from July 4, 2007, lays down specific requirements for the various stages in the life of the F-Gas from production to destruction.

In these and other documents related to the attempts of humanity to reduce anthropogenic influence, considerable space is given to refrigerants as one of the main sources of global warming, ozone depletion, impacts on human health and other adverse effects [4].

IRTIIE Vol. 4, No. 2, 2016 ISSN 1314-8788 (print), ISSN 1314-8796 (online), doi: 10.15547/artte.2016.02.008 


\section{IRTITE \\ Ipplied Researtches in Technics, Technologies and Bducition Journal of the Faculty of Technics and Technologies, Trakia University https://sites.google.com/a/trakia-uni.bg/artte/}

The purpose of this work is to analyze the classification of refrigerants under current legislation, and exploring methods to assess their impact on the environment and human health.

\section{ANALYSIS OF THE CLASSIFICATION OF REFRIGERANTS UNDER CURRENT LEGISLATION}

According to ISO 817: 2014 in Bulgaria was introduced classification of refrigerants in terms of their impact on the environment. It is made based on three criteria determining the impact of refrigerants on the environment and human health (Figure 1).

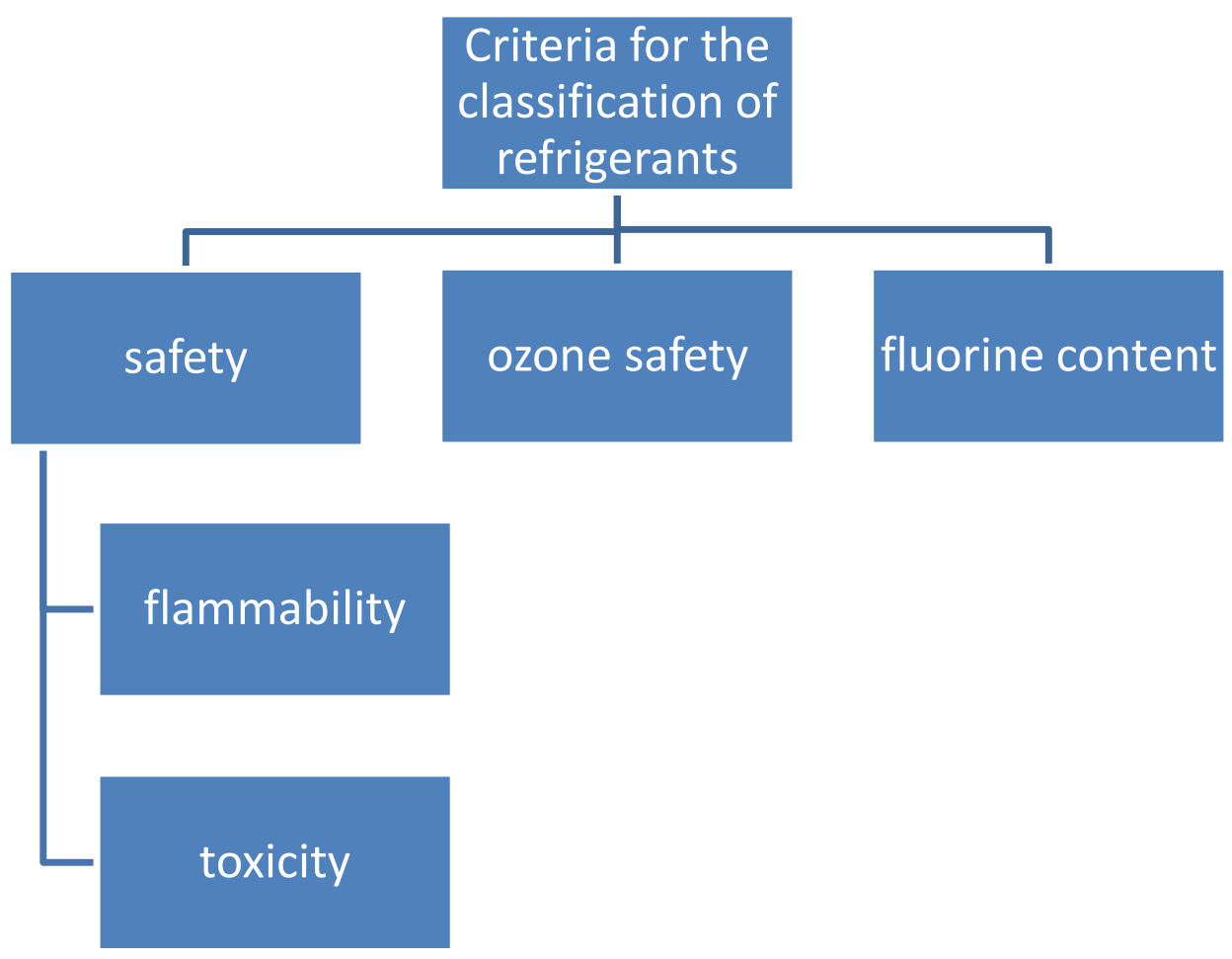

Figure 1. Classification of refrigerants, according to ISO 817: 2014

\subsection{Classification of refrigerants according to their safety}

According to the criterion safety for refrigerants are important factors flammability and toxicity. Depending on the lower flammability at atmospheric pressure and room temperature refrigerants are divided into four groups:

- First group - non-flammable - refrigerants that do not ignite the vapor phase at any concentration in the air;

- A second group - slightly flammable - refrigerants that the lower limit of inflammability at a concentration higher than or equal to $3.5 \%$ by volume, the heat of combustion less than $19000 \mathrm{KJ} / \mathrm{kg}$ and a speed of ignition of less than $0,1 \mathrm{~m} / \mathrm{s}$;

- A third group - flammable - refrigerants that the lower limit of inflammability at a concentration higher than or equal to $3.5 \%$ by volume, the heat of combustion less than $19000 \mathrm{KJ} / \mathrm{kg}$; 


\section{ARTTR $Y^{2}$}

Ipplied Reseitrches in Technics, Technologies and Bductition

Journal of the Faculty of Technics and Technologies, Trakia University https://sites.google.com/a/trakia-uni.bg/artte/

- A fourth group - highly flammable - refrigerants that the lower limit of flammability at a concentration of less than or equal to $3.5 \%$ by volume, the heat of combustion greater than $19000 \mathrm{KJ} / \mathrm{kg}$.

According toxicity factor determining influence is the concentration of refrigerants in unit volume, as they relate to one of two groups:

- group A - refrigerants with an average concentration that have no harmful effects on nearly all workers who may be exposed on a daily basis that impact normal 8-hour day and 40 hour working week, as the value of the concentration is equal to or less lower than $400_{\mathrm{ppm}}$.

- group B - refrigerants with an average concentration that have higher chronic toxicity nearly all workers who may be exposed on a daily basis that impact normal 8-hour workday and 40-hour workweek, the value of concentration under 400ppm.

It is important to know that toxic decomposition products can be obtained not only from refrigerants, but are the result of contact with a flame or hot surfaces under certain conditions.

Under Regulation (EC) № 1907/2006 of the European Parliament and of the Council of 18 December 2006 concerning the Registration, Evaluation, Authorization and Restriction of Chemicals $(\mathrm{REACH})$ refrigerants are accompanied by an information sheet describing the manufacturer, composition, dangers, precautions and more.

Limits of flammability can be used to determine the guidelines for the safe handling of volatile chemicals. They are mainly used in the evaluation and ventilation requirements for handling of gases and vapors.

Generalized assessment of refrigerants presented in [2] classifies them into the following groups of safety (Table 1 ):

Table 1. Groups of safety defined by the flammability and toxicity

\begin{tabular}{|l|c|c|}
\hline High flammability & A3 & B3 \\
\hline Low flammability & A2 & B2 \\
\hline No flame spread & A1 & B1 \\
\hline & Low toxicity & High toxicity \\
\hline
\end{tabular}

If there has any doubt on which group to carry refrigerant, it must be classified in that group requiring more stringent precautions.

Very often in practice the refrigerant is a mixture of different refrigerants. Then assessment is carried out for each criterion based on the individual components as a single component refrigerant.

\subsection{Classification of refrigerants according to their impact on the ozone layer}

On the reduction of the ozone layer affect many factors and atmospheric phenomena that react with ozone $\left(\mathrm{O}_{3}\right)$ and transform it into oxygen $\left(\mathrm{O}_{2}\right)$. The biggest impact are refrigerants, because of the specific chemical composition - content of fluorine $(\mathrm{F})$, chlorine $(\mathrm{Cl})$, bromine $(\mathrm{Br})$ and hydrocarbons $(\mathrm{CH})$. This is the basis on which are classified refrigerants in [2]:

- Refrigerants of the first group - CFC- refrigerants that contain fluorine, chlorine and highly ozone active, e.g. R11, R12, R13, R113, R114, R115 and mixtures R500, R501, R502, $\mathrm{R} 506$. These refrigerants have been replaced and its production is strictly prohibited.

- Refrigerants in the second group (hydrochlorofluorocarbons):

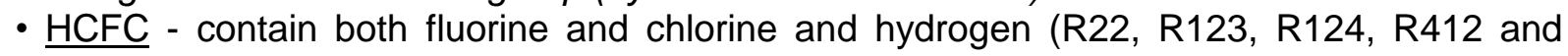
mixtures R401A, R401B, R402Q, R506);

IRTIIE Vol. 4, No. 2, 2016 ISSN 1314-8788 (print), ISSN 1314-8796 (online), doi: 10.15547/artte.2016.02.008 
- FS- only contain fluorine (R14, R116, R218 and mixtures R508);

- HFC- hydrogen fluoride (R23, R32, R125, and mixtures R407C, R410A, FX40).

These refrigerants are a temporary solution and in accordance with Directive №1804 / 2003 is a schedule for their prohibition of the use in national legislations.

In Bulgaria, according to data from the National Survey and develop a national strategy for phase-out of hydrochlorofluorocarbons in Bulgaria [8] 2008 of refrigerants greatest quantity is used by the group HFC - 76,684 $\mathrm{kg}$ and by the group HCFC - 17,149 kg, mainly in air conditioners and heat pumps.

This use corresponds with the stated quotas for our country for the use of refrigerants by these groups as currently we fulfill requirements for the 2020.

- Refrigerants from a third group - HC - these are hydrocarbons containing only carbon and hydrogen, without fluorine and chlorine (R170, R290, R600, R600A, R1270 and mixtures $\mathrm{R} 290$ / R600A). The shortcomings of these groups refrigerants is their flammable and the risk of ignition.

\subsection{Classification of refrigerants to the content of fluorinated greenhouse gases}

Gases, which containing fluorine although they have no ozone-depleting properties have a higher potential for global warming and the negative impact on climate change. Under the Protocol of the third evaluation of the IPCC (Intergovernmental Panel on Climate Change) that is indicative of the reflectivity of well-mixed greenhouse gases that represents the combined effect of the differing times these gases remain in the atmosphere and their relative effectiveness in absorbing infrared radiation. This indicator compares the warming effect over time per unit mass of a given greenhouse gas in today's atmosphere to carbon dioxide.

In the Proposal for a Decision of the European Parliament and the Council on the Common Program of the European Union for Environmental Action 2020 "Prosperity within our planet" adopted at the 7th meeting of the commission, February 19, 2013 is proposed to reduce at least $20 \%$ of greenhouse gases.

Most fluorinated greenhouse gases which have a high global warming potential are controlled under the Framework Convention of the United Nations on Climate Change and the Kyoto Protocol.

Legislation in Bulgaria prohibits the use of refrigerants of HCFC group from 01.01.2007. Increasing application are cooling systems that use mineral zeolite adsorbent for water and methanol as refrigerant. Its mechanism of action of thermodynamic cycle adsorptiondesorption [6]. In legislation adopted in our country in detail the question of control and collection of waste substances such as refrigerants in refrigeration.

\section{ANALYSIS OF ASSESSMENT METHODS REFRIGERANTS UNDER CURRENT LEGISLATION}

The replacement of ozone active refrigerants with alternative activity is depending on complex factors. Generally, they must meet the following conditions. They must:

- be chemically stable and inert.

- having entered the atmosphere to disintegrate before reaching the stratosphere;

- have solubility in refrigeration oils have high dielectric properties;

- have low freezing point;

- be compatible with the elements of the installation;

- be easily detectable leaks;

- be non-toxic or very low toxicity and flame;

IRTIIE Vol. 4, No. 2, 2016 ISSN 1314-8788 (print), ISSN 1314-8796 (online), doi: 10.15547/artte.2016.02.008 


\section{IRTTIE}

Ipplied Researl reses in Technics, Technologies ind Bducation Journal of the Faculty of Technics and Technologies, Trakia University https://sites.google.com/a/trakia-uni.bg/artte/

- have low cost.

Hydrocarbons group HC has one of the good solutions. They have some attributes that have the opportunity to explore the possibilities for their widespread use as refrigerants:

- they have zero ozone depletion potential;

- they have Low potential for warming;

- as a waste product from the oil industry, they can be profitably processed and delivered;

- they can be combined with all used in refrigeration substances;

- they can operate with lower temperatures of compression;

- they do not contain particles that do not form decomposition acids;

- they have good solubility of the hydrocarbons may lead to dilution of the oil and deterioration of lubrication;

- the necessary quantity of the filling of the installation is considerably less;

- they have better energy performance of hermetic compressors for household appliances.

The main disadvantage of hydrocarbons from $\mathrm{HC}$ group is that they are flammable and there is a danger of spontaneous combustion.

The data for these refrigerants are given in Table 2.

Table 2. Characteristics of refrigerants from group $\mathrm{HC}$

\begin{tabular}{|c|c|c|c|c|c|c|}
\hline $\begin{array}{c}\text { An } \\
\text { indication } \\
\text { of the } \\
\text { refrigerant }\end{array}$ & Refrigerant & $\begin{array}{c}\text { Chemical } \\
\text { formula }\end{array}$ & $\begin{array}{c}\text { Molar } \\
\text { mass, } \\
\mathrm{kg} / \mathrm{kmol}\end{array}$ & $\begin{array}{c}\text { Auto ignition } \\
\text { temperature, } \\
0\end{array}$ & $\begin{array}{c}\text { Limit concentrations } \\
\text { firing in the air }\end{array}$ \\
\hline $\mathrm{R} 170$ & Ethane & $\mathrm{CH}_{3} \mathrm{CH}_{3}$ & 30 & 515 & $\begin{array}{c}\text { Lower } \\
\text { limit } \\
\mathrm{kg} / \mathrm{m}^{3}\end{array}$ & $\begin{array}{c}\text { Upper } \\
\text { limit } \\
\mathrm{kg} / \mathrm{m}^{3}\end{array}$ \\
\hline $\mathrm{R} 290$ & Propane & $\begin{array}{c}\mathrm{CH}_{3} \mathrm{CH}_{2-} \\
\mathrm{CH}_{3}\end{array}$ & 44 & 470 & 0,037 & 0,19 \\
\hline $\mathrm{R} 600$ & Butane & $\mathrm{C}_{4} \mathrm{H}_{10}$ & 58,1 & 365 & 0,038 & 0,171 \\
\hline $\mathrm{R} 600 \mathrm{a}$ & Isobutane & $\mathrm{CH}_{\left(\mathrm{CH}_{3}\right)_{3}}$ & 58,1 & 460 & 0,043 & 0,202 \\
\hline $\mathrm{R} 1150$ & Ethylene & $\mathrm{CH}_{2}=\mathrm{CH}_{2}$ & 28,1 & 425 & 0,031 & 0,391 \\
\hline $\mathrm{R} 1270$ & Propylene & $\mathrm{C}_{3} \mathrm{H}_{10}$ & 42,1 & 455 & 0,043 & 0,174 \\
\hline R 50 & Methane & $\mathrm{CH}_{4}$ & 16 & 645 & 0,032 & 0,098 \\
\hline
\end{tabular}

These data are given in European Standard [1]. Additionally provided herein restrictions in the international standard [2] prescribe additional and upper limit concentrations of refrigerants from this group.

To this moment for measuring greenhouse gas used Global warming potential (GWP). It is a relative measure of how much heat a greenhouse gas traps in the atmosphere. It compares the amount of heat trapped by a certain mass of the gas in question to the amount of heat trapped by a similar mass of carbon dioxide. A GWP is calculated over a specific time interval, commonly 20,100 or 500 years. GWP is expressed as a factor of carbon dioxide. In the Fifth Assessment Report of the Intergovernmental Panel on Climate Change, methane has a lifetime of 12.4 years and with climate-carbon feedbacks a global warming potential of 86 over 20 years and 34 over 100 years in response to emissions. User related choices such as the time horizon can greatly affect the numerical values obtained for carbon dioxide equivalents. For a change in time horizon from 20 to 100 years, the GWP for methane decreases by a factor of approximately 3 . The substances subject to restrictions under the Kyoto protocol either are rapidly increasing their concentrations in Earth's atmosphere or have a large GWP. 


\section{ART'TE

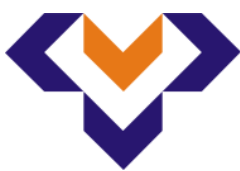 \\ Ipplied Resseirl ches in Technics, Technologies and Bductition \\ Journal of the Faculty of Technics and Technologies, Trakia University https://sites.google.com/a/trakia-uni.bg/artte/}

The GWP depends on the following factors:

- the absorption of infrared radiation by a given species

- the spectral location of its absorbing wavelengths

- the atmospheric lifetime of the species

Thus, a high GWP correlates with a large infrared absorption and a long atmospheric lifetime. The dependence of GWP on the wavelength of absorption is more complicated. Even if a gas absorbs radiation efficiently at a certain wavelength, this may not affect its GWP much if the atmosphere already absorbs most radiation at that wavelength. A gas has the most effect if it absorbs in a "window" of wavelengths where the atmosphere is fairly transparent. The dependence of GWP as a function of wavelength has been found empirically and published as a graph.

Because the GWP of a greenhouse gas depends directly on its infrared spectrum, the use of infrared spectroscopy to study greenhouse gases is centrally important in the effort to understand the impact of human activities on global climate change.

The adopted classification system and an indication of refrigerants do not give an overall assessment of their impact on the environment and human health. So look for a methodology for determining a complex impact. Such a method is proposed in [1], where in Annex B describes the methodology for determining the total equivalent Warming Potential (TEWI). It includes an assessment of the complex interaction of both individual refrigerant and a complex system as a whole.

The index TEWI is designed to calculate the contribution to global warming resulting from the use of refrigerants for process cooling and heating. It takes into account both the direct impact of refrigerant on the climate and indirect impact on energy consumption for normal operation of the refrigeration system.

For a given system TEWI include:

- Direct effect on global warming under certain conditions of refrigerant leakage

- Direct effect on global warming due to greenhouse gases emitted from insulation and other components, if any

- Indirect effect on global warming from $\mathrm{CO}_{2}$ emissions associated with the production of energy for the operation of the refrigeration system.

There are a number of research teams working on methodologies for calculating TEWI that will be explored at a later stage.

\section{CONCLUSION}

- In the recent years much has been done on the replacement of ozone-depleting refrigerants with ozone-safe. However, work on search, development, testing and implementation of new ozone-safe refrigerants is continuing. We have not yet found the ideal substitutes mainly used refrigerants such as R12, R22, R502.

- Of the total analysis may be noted that energy efficiency is much more important goal for reducing global warming by cooling itself. It turns out that a refrigeration machine that is efficient and uses a refrigerant with high global warming potential could be a better choice than not efficient refrigeration machine working refrigerant with low global warming potential, but there is a large energy.

- Refrigerants from the group of hydrogen fluoride (HFC), which are alternatives to those already prohibited (R12, R22) have a dual effect. On the one hand does not deplete the ozone layer and on the other, as the main component of fluorinated greenhouse gases (HFCs, PFCs, SF6) - F gases they have very high global warming potential as strongly influenced in the process of global warming.

IRTIL Vol. 4, No. 2, 2016 ISSN 1314-8788 (print), ISSN 1314-8796 (online), doi: 10.15547/artte.2016.02.008 


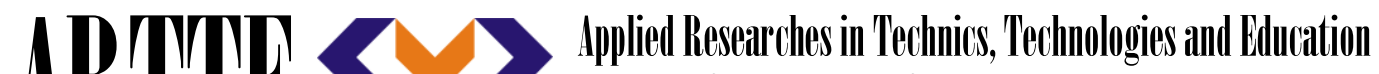 Journal of the Faculty of Technics and Technologies, Trakia University https://sites.google.com/a/trakia-uni.bg/artte/}

- The current methodology in accordance with regulations to determine the impact of refrigerants on the environment suggests using common equivalent Warming Potential TEWI. There are looking for new more accurate methods of determining influence.

\section{REFERENCES:}

[1] BDS EN 378-1: 2008 + A2. "Refrigerating systems and heat pumps. Safety requirements for the environment. Part 1: Basic requirements, definitions, classification and selection criteria".

[2] BDS ISO 817: 2014 "Designation and classification of safety".

[3] Framework United Nations Convention on Climate Change, ratified by law, adopted by the 37th National Assembly on 16.03.1995.

[4] Regulation (EC) № 2037/2000 of the European Parliament and of the Council of 29 June 2000 on substances that deplete the ozone layer.

[5] The Kyoto Protocol to the Framework Convention of the United Nations on Climate Change, ratified by law, adopted by the 39th National Assembly on 17.07.2002 - SG. 72 of 25.07.2002, was issued by the Ministry of Environment and Water, prom. SG. 68 of 08.19.2005, effective from 16.02.2005.

[6] Georgiev R., K. Peichev, A. Pavlov, K. Trendafilov, G. Dineva, I. Binev, Study of a zeolite-water experimental refrigeration module intended for animal raising, Agricultural science and technology, vol.5, No1 , 2013, ISSN 1313-8820, pp.58-61.

[7] Binev I., C. Rasheva N. Georgieva, Technical and Economic Assessment of energy saving measures for the building of the faculty "Engineering and Technology" Yambol, Scientific Works of the University of Food Technologies - Plovdiv, Volume LXII, 2015.

[8] National research and development of a national strategy for the phase-out of hydrochlorofluorocarbons in the Republic of Bulgaria, Sofia, April 2010. 